\title{
Trends of Maternal Mortality in Damaturu, Yobe State, Nigeria
}

\author{
Mustapha Adam Kolo (PhD) \\ Department of Geography, \\ University of Maiduguri, Nigeria
}

\author{
Muhammad Chutiyami (MSc) \\ College of Nursing and Midwifery \\ Damaturu, YobeState, Nigeria
}

\author{
Isyaku Ibrahim (BSc) \\ Bubal Wada-Biu, Borno State, \\ Nigeria
}

\section{ABSTRACT}

Yobe state is one of the core state in the north east geopolitical zone of Nigeria, a zone that is characterized by second highest maternal mortality in the country, after north-west. This study aimed to examine trends of maternal mortality in Yobe State, a case study of General Sani Abatcha Specialist Hospital Damaturu. One consultant gynecologist, three midwives, and forty women of child bearing age participated in the study. An Ex-post factor research design was adopted using maternity attendance record and structured interview. The data was analyzed using descriptive statistic and presented on graphs/tables. It was identified that maternal mortality decline steadily from 2010 to 2013, but there was relative increase in 2014 , both of which were associated with ante-natal care coverage and hospital deliveries. The study further identified ways of improving maternal health using provision of adequate trained health personal, and provision of essential facilities in hospitals among others. Based on these findings, it was concluded that maternal mortality decreases in yobe over the years, but the figure still remain unacceptably high. It is thus recommended that Government, Non - governmental organization and philanthropist to be more committed in providing modern equipments in hospitals and primary health care centers.

\section{KEYWORD}

Trends, maternal mortality, Prevalence, Damaturu, Yobe, Nigeria

\section{INTRODUCTION}

Achieving the Millennium Development Goals (MDGs) of reducing maternal mortality ratio by three quarter between 1990 and 2015, is far from target, particularly in Sub-Saharan Africa countries, where access to basic obstetric services is very poor (Hofman and Mohammed, 2014; Ager et al., 2015;
WHO 2014). It has been a challenge to observe the exact progress made over the years, due to lack of reliable and accurate maternal mortality data (WHO and UNICEF, 2014). Globally, there was an estimated 289,000 maternal deaths in 2013 with a decline of 45 percent from 1990 (WHO 2014). The global Maternal Mortality Rate (MMR) in 2013 was 210 maternal deaths per 100,000 live births in comparison to 380 maternal deaths per 100,000 live births in 1990. However, hidden within these figures are enormous inequalities for instance; the MMR in developing regions was 14 times higher than developed regions (WHO, UNICEF, UNFPA, World Bank and UN, 2014). Every region has advanced to a certain level, although level of maternal mortality remains unacceptable high in sub-Saharan Africa despite the little advances made in some of the countries. Almost all maternal deaths can be preventable with reasonable investment, considering the huge disparities found between the richest and poorest countries, for instance, the lifetime risk of maternal death in industrialized countries is 1 in 400 versus 1 in 51 in countries classified as "least developed," (UNICEF, 2013).

Nigeria has 630 maternal deaths in 2010 as compared to Kenya 360, South Africa 300, United State 21, United Kingdom 12 and Belgium 8, all these deaths per 100,000 live births. The profile of maternal mortality trends in Nigeria as published by the United Nations based on the estimates for 1990-2013 was gradually reducing. The report "Trends in Maternal Mortality: 1990-2013" presents internationally comparable maternal mortality ratio (MMR) estimates, whereby Nigeria is said to have declined in maternal mortality by $52 \%$ between 1990 and 2013, (Mamaye, 2015; Ager et al., 2015; WHO, 2014). Despite these progress, the country accounts for $13 \%$ global maternal mortality rates with an estimated 36,000 women dying in pregnancy or child birth each year, out of which 5500 of these deaths are among teenage mothers. These figures were reflected in Nigerian Demographic \& Health Survey (2013), 
which noted that 70 percent of the maternal deaths in Nigeria are due to four conditions: hemorrhage, eclampsia, sepsis and abortion complications. The data made available by the United Nations Population Found (UNPF) noted that over the last 20 years, Nigeria has made significant progress in reducing the maternal mortality ratio.

Yobe state, one of the Nigerian north eastern states that is characterized by high maternal death in the region is faced with an additional problem of Boko Haram insurgency. Of the four northern Nigerian states (Jigawa, Katsina, Zamfara and Yobe) that are estimated to have the highest maternal mortality rates in the country, only Yobe is affected with Boko Haram difficulties. This drastically increases the maternal mortality figure as well as increase in the number of vulnerable mothers and children (Ager et al., 2015). The health system in the state is fragmented between State Ministry of Health (SMOH), Hospital Management Board (HMB) and State Primary Health Care Management Board (SPHCMB). For instance, primary health care is provided by SPHCMB. The SPHCMB is responsible for coordinating the activities of Primary Health Care (PHC) facilities. The facilities are distributed across 17 Local Government Areas (LGAs) of the state, every LGA is managed by a PHC coordinator responsible for coordinating all primary health care activities within the LGA, also for the purpose of management, the LGAs are divided into 6 health zones headed by a zonal officer responsible for coordinating health activities within the zone. All secondary facilities are being managed by HMB while the SMOH develop policies and strategies for the health sector as well as coordinate the activities of the Ministries, Departments and Agencies (Yobe State Ministry of Health, 2014)

This study therefore aims to investigate the trends of maternal mortality in Yobe state, Nigeria. The study is confined to General Sani Abatcha Specialist Hospital Damaturu, as it is the biggest hospital with advance maternity services in the state.

\section{METHODOLOGY}

Research Design - This study adopts Ex-post factor research design. The choice of this research design was based on the fact that it seeks to find out the factors that are associated with certain occurrence, outcomes, conditions, or types of behavior by analysis of past events or of already existing conditions (Akuezulo and Agu, 2003). The method will therefore afford the study to investigate various trends in maternal mortality in Damaturu, Yobe state from 2010 to 2014.

Research Setting - Damaturu is located between latitude $11^{0} 44^{\prime} \mathrm{N}$ to $11^{0} 45^{\prime} \mathrm{N}$ and longitude $11^{0} 56^{\prime} \mathrm{E}$ to $11^{0} 58 \mathrm{E}$. It is the capital of Yobe state which comes into being in August $27^{\text {th }} 1991$. The state is one of the 36 states in Nigeria, which has 17 local government areas, of which one is Damaturu local government. Damaturu has the total land area of $3,366 \mathrm{~km}$ with total population of 88,014 as of the last census data i.e. 2006 population and housing census.

Population and Sample - The study focused on the trends of Maternal Mortality in General Sani Abatcha Specialist Hospital Damaturu, the capital of Yobe State. The population of the study comprised of women of child bearing age, doctors, and midwives of General Sani Abatcha Specialist Hospital Damaturu, Yobe State.

Sample Techniques - The sampling techniques employed in this are simple random sampling method. The selection of doctor and midwives was done through probability sampling technique. This gives all members of the population equal chance of being selected. There are four (4) permanent gynecology doctors in general Sani Abatcha Specialist Hospital Damaturu. The choice of one (1) doctor is based on one third $(1 / 3)$ of number of the gynecology doctors in the Hospital. The formula used is $4 / 3=1.33$, i.e one (1) gynecology doctor. The choice of three (3) health personal (midwives) was also based on the $1 / 3$ number of the health personnel's in the maternity wards of general Sani Abacha specialist hospital Damaturu. This is because there are only (9) registered midwives in the ward. The fourty (40) women of child bearing age were selected through accidental sampling technique, using women who visited the maternity centre of the hospital at the time of the study.

Data Collection Instrument - The instrument used for collecting data for the study is maternity attendant record. In-depth interviews question was developed, the questions were designed with the objectives of the study in minds. The interview was administered to respondents through face to face interaction. The information gathered from the interview is 
confidential and purely academic. The interaction helps in finding silent issues. The interview took two consecutive weeks. The researcher used pen and paper in writing the responses of the respondents. The introductory letter helped in collecting data on maternity record in General Sani Abatcha Specialist Hospital Damaturu.

Ethical Consideration - The fact this is a primary study, a number of ethical considerations were observed before conduct of the study. Firstly, a formal ethical approval was obtained from University of Maiduguri research and ethical committee after filling the appropriate ethical forms. Similarly, permission was sought from the Chief Medical Director (CMD) of General Sani Abatcha Specialist Hospital Damaturu to conduct the study in the institution. After gaining approval by the CMD, another permission was obtained from the Head of the Maternity Unit, to conduct the study in the Unity after explaining in detail the purpose of the study. Finally, only participants who voluntarily agreed to participate in the study were included. The participants (Doctor, Midwives and Women) were given a consent form that they read and sign before they were enrolled for the study. Confidentiality and anonymity of information was ensured throughout the study.

\section{RESULTS}

The graph is used to present the data obtained from General Sani Abatcha Specialist Hospital Damaturu (GSASH) Damaturu i.e. the maternity attendance record from year 2010 to 2014. This graph is used because it clearly project the ante - natal care attendance, Hospital delivery and maternal death. The information volunteered from health workers and women was used in discussing the graphs.

\section{Figure 1: Antenatal Care (ANC) Attendance at General Sani Abatcha Specialist Hospital, Damaturu}

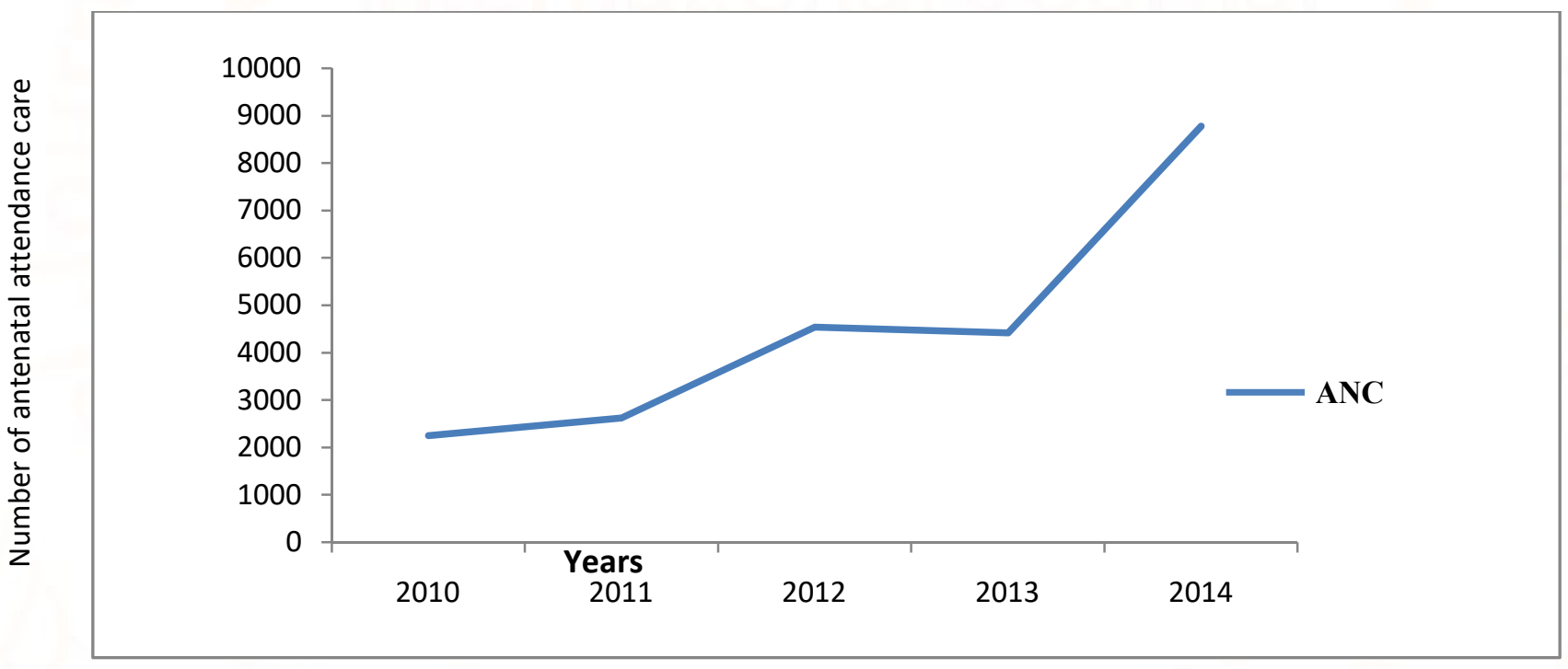

Source: Field work, 2015

This graph shows that year 2014 has the highest number of antenatal care attendance with more than 8,000 women while year 2010 has the lowest attendance record with just 2,251 who attended the antenatal care throughout the whole year from January to December. The graph indicates a gradual increase in attendance record from 2010 to 2014.

The interview shows that women patronizing the hospital especially the maternity unit was as a result of the free maternity drugs given in the hospital, alongside free cards, scanning and delivery fee. There is an awareness-ANC education woman on the importance of balance diet during pregnancy. Doctors and consultant gynecologist are also available at the hospital from Monday to Friday.

The high number of ante-natal care attendance in the year 2014 was recorded because of insecurity problem and migration- i.e people from other local government areas of the state are relocating to the capital city of Damaturu. 


\section{Figure 2: Hospital Delivery at General Sani Abatcha Specialist Hospital, Damaturu}

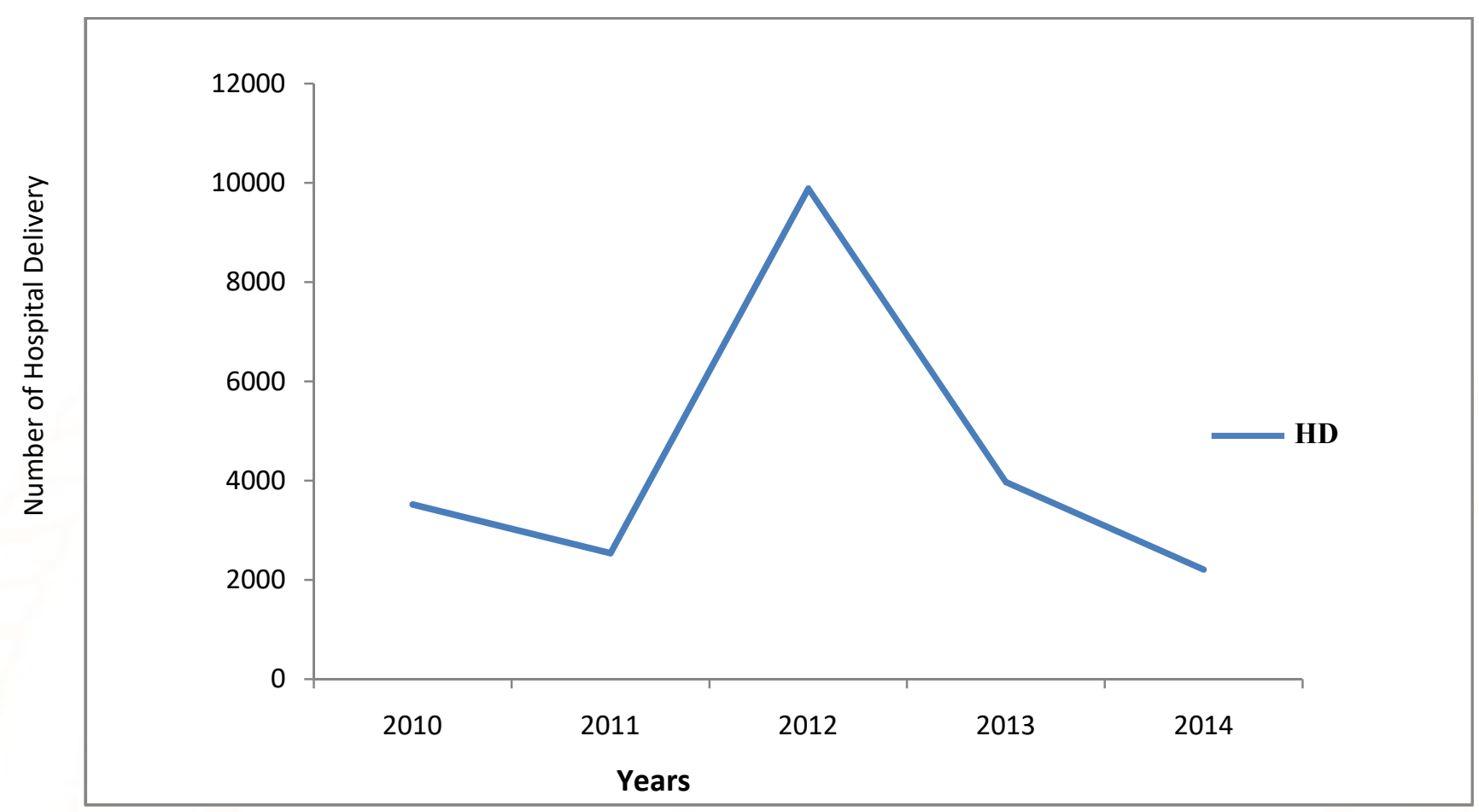

Source: Field work, 2015

The graph indicates that the year 2012 has the highest hospital delivery with a total number of 9,891 . This is followed by year 2013 with 3,978 hospital delivery. And the hospital delivery is very low in year 2011 and 2014 with total number of 2,541 and 2,211 respectively.

From the interview, it was revealed that year 2012 has the highest hospital delivery because it is the very year Yobe state government introduction free antenatal and post natal care services in the state. There are also high number of midwives recruited in the hospital as well as availability of delivery facilities.

The year 2011 recorded low hospital delivery because of displacement of people as a result of the insecurity (Boko Haram). Due to the insecurity in the year, there is no doctors and consultant gynecologist in the entire unit. Similarly, the, free antenatal and post-natal service was not introduced in the state. 
Table 1: Maternal death at General Sani Abatcha Specialist Hospital, Damaturu

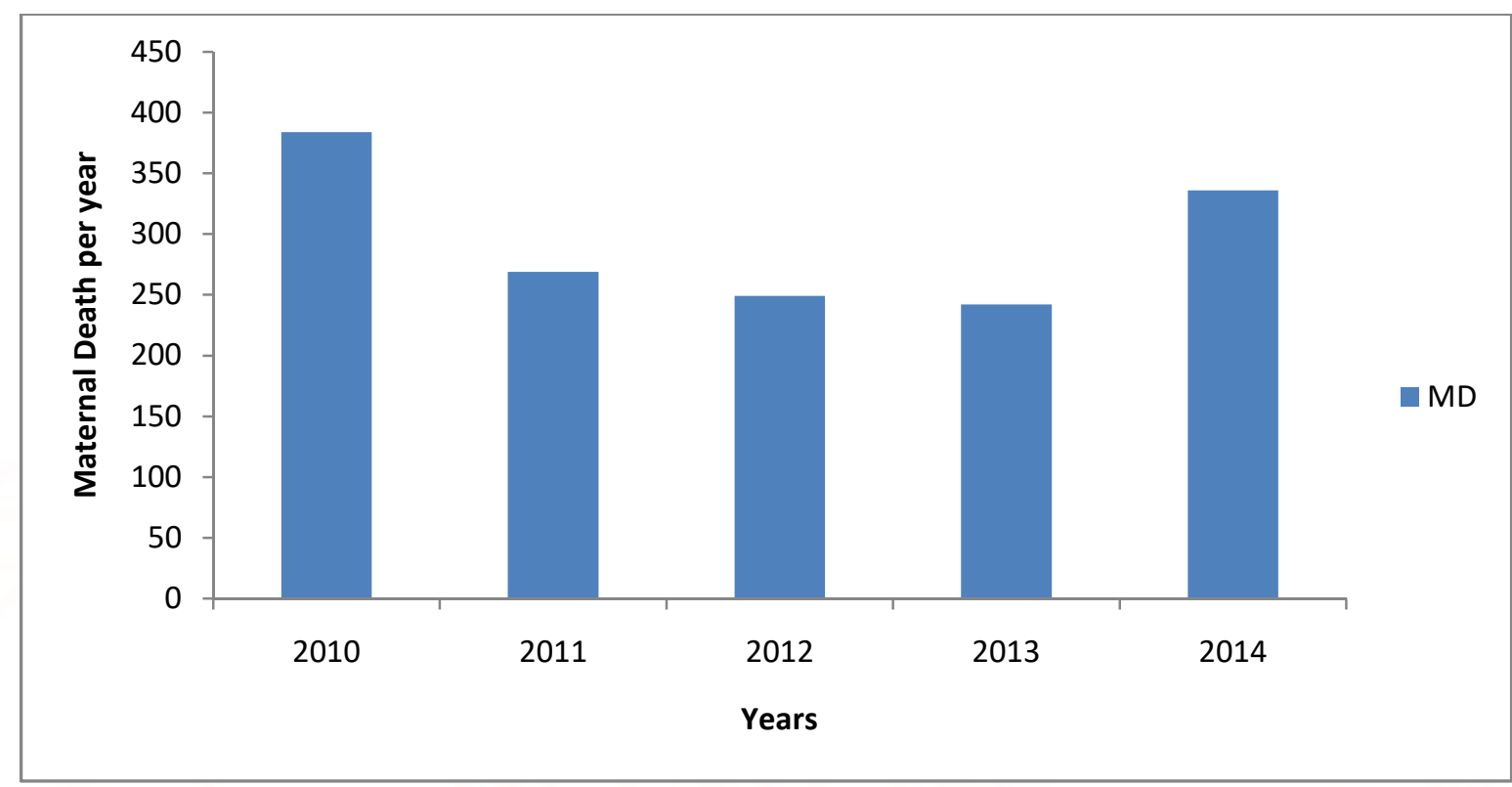

Source: Field work, 2015

This graph shows the years 2010 and 2014 with highest material death, with a total number of 384 and 336 respectively. However, year 2012 and 2013 recorded less maternal death, with 249 and 242 deaths respectively. From the interview, it was revealed that the causes of high hospital death in the year 2010 and 2014 is because of complications like excessive bleeding, eclampsia and high blood pressure etc. during pregnancy and after birth, the ignorance on the importance of Ante-natal care (ANC) also contributed to the high death rate in the hospital, lack of modern equipment and well skilled birth attendance, likewise the displacement of people from various contribute to the high number of hospital death in General Sani Abatcha specialist Hospital Damaturu.

\section{Discussion}

This study was designed to examine the trends of maternal mortality in General Sani Abacha Specialist Hospital Damaturu, Yobe state. Findings from Table 1 shows Antenatal Care (ANC) Attendance at General Sani Abatcha Specialist Hospital. From the graph analysis, it was indicated that there is a decrease in maternal death from year 2010 to 2013, where in 2010, 380 women died, in 2011, 269 women died, in 2012, 249 women died and in 2013, only 242 women died. This decline in maternal death is in line with the report of UNICEF (2013), WHO, UNICEF, UNFPA, World Bank and UN (2014) and Mamaye
(2015), who stated that globally there is declined in maternal death and Nigeria is not exempted. However, the year 2014 as indicated on the graph shows a slightly increase in maternal death above the previous three years. The situation in the prevalence rate can be described as low because out of 3,978 deliveries in the year 2013, only 242 lost their lives. This is significant because the nation itself (Nigeria) has made significant progress in reducing the maternal mortality ratio. On the other hand, the finding of the study also shows a steady increase in the number of women attending antenatal care services in the hospital over the four year period. This is to say that decrease in the mortality rate coincide with increase in antenatal care coverage; hence a number of the predisposing factors to maternal deaths were taken care of during the ante-natal services. This is supported by the findings of Hofman and Mohammed (2014) in selected northern Nigerian states, which shown a maternal mortality decline in the study areas with corresponding increase in antenatal care coverage. However, finding of this study indicated a dramatic decrease in the number of hospital deliveries, particularly in the year 2014. This was indicated to be associated with the insurgency and civil unrest affecting the state during that time, thus a number of women migrated out of the state.

The finding of this study further shows from the opinion of the health personals (consultant gynecologist and midwives), that availability of drugs 
and delivery facilities, early detection and treatment of problems and complications in pregnancy, promoting healthy behavior in pregnancy, awareness on birth preparedness and early treatment of complications during delivery would help remedy the high maternal mortality rate in General Sani Abacha Specialist Hospital Damaturu in particular and Yobe state at arge. This is in line with recommendations of Ager et al., (2015) and Hofman and Mohammed (2014), who necessitates the need for more commitment interms of human and material resources in Nigerian hospitals.

\section{CONCLUSION}

Based on the findings of this study, it was concluded that Yobe state of Nigeria is still far from reaching its target of reducing maternal mortalities in the state, despite the advances and progress made over the years. Therefore, Government, Non - governmental organizations and philanthropists should help in providing modern equipments, recruitment of more staff and enhancing primary health care services.

\section{ACKNOWLEGEMENT}

The researcher sincerely the Chief Medical Director as well as the head of maternity unit of General Sani Abatcha Specialist Hospital Damaturu for cooperation and granting permission to conduct this study. Our appreciation also goes to the respondents, who voluntarily participated in this study.

\section{REFERENCE}

1) Akuezuilo, E. O. and Agu, N. (2003), Research and statistics in Education and social science. Method and application: (revised and updated edition), Nuel centi Publishers and Academic Press Ltd, Awka, Nigeria

2) Ager A.K., Lembani, M., Mohammed, A., Ashir, G.M., Abdulwahab, A., Pinho, H.D., Delobelle, P. and Zarowsky, C. (2015) Health service resilience in Yobe state, Nigeria in the context of the Boko Haram insurgency: a systems dynamics analysis using group model building. Complict and health, 9:30.

3) Hofman, J.J. and Mohammed, H. (2014) Experiences with facility-based maternal death reviews in northern Nigeria. Elsevier, 126(2):111114.

4) Margaret Myles (2001) Text Book for midwives $12^{\text {th }}$ edition National Health policy (2004) Federal Ministry of Health Oxal et (2005) preventive Medicine in Developing Countries Edward Arnold publishers.

5) OJO O.A. and Briggs, E.B. (2005) A textbook for midwives in the tropics, $4^{\text {th }}$ edition.

6) Mairami (2000) Factors associated with law utilization of facilities for deliveries journal of community medicines' Maternal mortality Estimates Developed by W.H.O.

7) Mamaye, (2015) Maternal Mortality in 19902013: Available at: nigeria.www.mamaye.org.ng/en/evidence/material -mortality.

8) Morgan, K.J. and Eastwood, J.G (2014) social determinants of maternal self-rated health in south western Sydney, Australia BMC. Research Notes 7(1-12).

9) WHO, UNICEF, UNFPA, World Bank and UN (2014) Trends in maternal mortality:1990 to 2010.

10) UNICEF (2013) Monitoring the situation of children and Women. Available at: unicef. Org. /maternal -health /maternal-mortality Retrieved $23^{\text {rd }}$ April, 2015.

11) WHO, (2014) Trend in Maternal mortality, 1990 to 2013. Available at:

www.who.int/reproductivehealth/publications/mo nitoring/www.who.int/reproductivehealth/publicat ions/monitoring.maternal-mortality-2013/en/

12) Yobe State Ministry of Health (2014) HEALTH SECTOR MEDIUM TERM SECTOR STRATEGY (Rollover 2015 - 2017). Yobe state Government, Nigeria. 